\title{
TECHNOLOGY CHOICE AND THE COST REDUCTION POTENTIAL OF PHOTOVOLTAICS
}

\author{
Jessika E. Trancik ${ }^{1,2}$, Ken Zweibel ${ }^{3}$ \\ ${ }^{1}$ Santa Fe Institute, Santa Fe, New Mexico \\ ${ }^{2}$ Earth Institute, Columbia University, New York, NY \\ ${ }^{3}$ National Renewable Energy Laboratory, Golden, CO
}

\begin{abstract}
We use a combination of system component analyses and individual experience curves for crystalline silicon (x-Si) modules, thin-film (TF) modules, and the balance of system (BOS) components, to compare future growth scenarios for photovoltaics (PV). The growth rates of TF and $x$-Si technologies are varied, while overall PV growth is held constant at $30 \%$. For each of these scenarios, we estimate the total investment required for $\mathrm{PV}$ to reach a break-even point with fossil fuel based generation; and we investigate the intrinsic/lowest achievable costs from an analysis of potential materials, processing, and efficiency improvements. Our results show that a high growth rate (50 to $70 \%$ per year) of new technologies with low intrinsic costs could decrease the total investment required to reach break-even by up to 70 billion USD, as compared to a scenario where $\mathrm{x}-\mathrm{Si}$ continues to dominate the market. Furthermore, the system component analysis indicates that existing TF modules can reach the low cost levels assumed in the experience curve model. These results suggest that the future growth of photovoltaics (PV) is dependent on which PV technologies grow most rapidly. New, low intrinsic cost technologies that are successfully able to enter the market could dramatically increase the potential for PV to become a globally significant energy conversion technology within the next two decades.
\end{abstract}

\section{INTRODUCTION}

Since early commercial production in the mid 1970s, average PV module costs have decreased from $\sim 70$ USD/W $W_{p}$ to $\sim 3$ USD/W $W_{p}$.[1] However, the cost per kilowatt-hour (kWh) of PV electricity is in many circumstances higher by 2-5 times than the cost of fossil fuel alternatives. PV will need to reach costcompetitiveness in a variety of settings, in order to make a significant contribution to the global energy mix. This is likely to require investment in both supply-push and demand-pull support programs. In this paper we investigate how technology choice affects the scale of the investment required to achieve a reduction in $\mathrm{PV}$ costs, and thus how technology choice impacts the potential for PV growth.

Empirical data can be used to derive an experience curve which tracks the decrease in unit cost for a technology associated with an increase in cumulative production. This can then be used as a basis for projecting future decreases in costs. The study presented here differs from previous work [2-4] in that it tracks separate experience curves for PV technologies that have fundamentally different physical characteristics. This experience curve based model is then complemented by a system components analysis - an engineering estimate of how improved efficiencies and refinements in processing steps and production of components at a large scale will affect costs. Previous system component analyses have been published[5,6], but these were not correlated to experience curve projections.

The PV technologies addressed in this study are the group of thin-film (TF) modules and crystalline silicon (x-Si) modules (which includes both polycrystalline and single crystal versions). The $x$-Si modules account for $92 \%$ of cumulative PV production to date (through 2004).[1] This study focuses on the TF modules for which reliable production data is available: amorphous silicon (a-Si), polycrystalline cadmium telluride (CdTe), and polycrystalline copper indium diselenide (CulnSe $\mathrm{S}_{2}$ alloys, or $\mathrm{CIS}$ ). Of these, a-Si and CdTe are the most mature, with measurable cumulative sales in the PV marketplace. (Table 1) In order to justify tracking individual experience curves for TF and $\mathrm{x}$-Si technologies, we point out that the TF technologies are different enough from $x$-Si to have limited learning spill-over. We also include in our model an experience curve for the balance of system (BOS) components, including a support structure, a current collection system, installation costs, and an inverter.

\begin{tabular}{|c|c|}
\hline Technology & $\begin{array}{c}\text { Cumulative } \\
\text { Production 2004 }\end{array}$ \\
\hline $\mathbf{C d T e}$ & $20 \mathrm{MWp}$ \\
\hline $\mathbf{a}-\mathbf{S i}$ & $310 \mathrm{MWp}$ \\
\hline $\mathbf{x}-\mathbf{S i}$ & $3482 \mathrm{MWp}$ \\
\hline $\mathbf{A l l} \mathbf{T F}$ & $340 \mathrm{MWp}$ \\
\hline All PV & $3820 \mathrm{MWp}$ \\
\hline
\end{tabular}

Table 1. Cumulative production by technology.[1]

\section{EXPERIENCE CURVE MODEL}

Experience curves plot the decrease in unit cost/price of a technology associated with an increase in its cumulative production.[7] Empirical data from numerous industries shows a power law relationship between the cumulative production and the unit cost/price.[8] Because data is available at the industry level for prices rather than costs, experience curves generally track prices. This is true for our study. 
Based on an experience curve that spans the last two decades, a doubling of cumulative production of PV modules corresponds to a price reduction of $\sim 20 \%$, and a progress ratio of $80 \%$. The progress ratio $P R$ is defined as:

$P R=(1-$ reduction unit $\cos t$ with doubling cumulative production $)$

An experience curve can be used to estimate future cost reductions, based on this progress ratio. Starting from the initial cumulative production $n_{0}$, to find cumulative production at time $t, n_{t}$, corresponding to a price at time $t$ of $c_{t}$ one can use the following expression.

$c_{t}=c_{0} \times\left(\frac{n_{t}}{n_{0}}\right)^{\alpha}, \quad$ where $P R=2^{\alpha}$

The price at time of break-even, $t=b$, is denoted $c_{b}$. Using equation 2 and setting $c_{t}$ to $c_{b}$ the cumulative production at break-even, $n_{b}$, can be predicted. The total cost $C$ of reaching the break-even point is then estimated by taking the integral of the experience curve from the initial cumulative production $n_{0}$, to the cumulative production at break-even $n_{b}$.

$$
C=\frac{c_{0}}{\alpha+1}\left(\frac{n_{b}^{\alpha+1}-n_{0}^{\alpha+1}}{n_{0}^{\alpha}}\right)
$$

In order to find a break-even year for PV and the total investment required to reach that point based on different grow rates for individual technologies, we model changes to the TF, $x-S i$, and BOS markets. We plot a single experience curve for TF; in effect this means we model TF as a-Si, because to-date a-Si sales have accounted for the largest fraction of TF sales.

In our model we assume that $\mathrm{x}-\mathrm{Si}$, TF and BOS all continue to grow. BOS annual growth follows that of the total PV market - $30 \%$, based on historical behavior. We vary the TF growth rate between $30-70 \%$ per year, and subtract from $\mathrm{x}$-Si production the amount needed to keep the total PV growth at $30 \%$. Growth rates for $\mathrm{x}-\mathrm{Si}$ do not exceed $30 \%$ in our model because this would almost immediately surpass the $30 \%$ limit we have set for PV growth. We use the same $P R$, of $80 \%$, for TF and the BOS as for $\mathrm{x}-\mathrm{Si}$, based on available data and communication with the industry.[1, 3, 9]

The cumulative production predicted for a certain year can be found using the following expression, where the time $t=2004+x, G R=$ growth rate, $n_{\text {oyearly }}=$ the annual production in the starting year, in our case the year 2004.

$n_{t}=n_{0}+\sum_{x=1}^{t}\left((1+G R)^{x} \times n_{0 \text { yearly }}\right)$

Based on equations 2 and 4 , one can find the cost reduction and cumulative production for TF modules, $x$-Si modules, and the BOS, for scenarios with different growth rate assumptions. By adding the module cost to the BOS cost (plus a BOS penalty, see explanation below) for the case of TF systems and separately for $\mathrm{x}-\mathrm{Si}$ systems, the break-even year and break-even cumulative production is found. One can also use the model to predict which of the systems (TF or $\mathrm{x}$-Si) will reach break-even first. The cumulative production at break-even, and the total cost required to reach the break even point can also be estimated. The total investment at break-even, $C_{\text {total, }}$ includes the investment required for growth of all components from all systems: $C_{T F}$ (TF modules), $C_{x-S i}(x-S i$ modules), $C_{B O S}(B O S)$, and $C_{B O S p e n a l t y}(B O S$ penalty).

$C_{\text {total }}=C_{T F}+C_{x-S i}+C_{B O S}+C_{B O S P e n a l t y}$

The additional cost of adding PV capacity instead of fossil fuel capacity is referred to as the cost gap, and is found by subtracting from $C_{\text {total }}$ the cost of adding the same amount of fossil fuel capacity, $C_{F F}$. This assumes that the cost of adding fossil fuel capacity remains at the break-even point $(\$ 1 / \mathrm{Wp})$ throughout the period under consideration. The cost gap can also be thought of as the societal investment required to reach break-even. A lower cost gap should make PV more attractive to tax-paying citizens and governments.

Cost gap $=C_{\text {total }}-C_{F F}$

Modules that have lower efficiencies require more of the 'area-related BOS' (support structures, wires, and installation costs) to produce the same amount of electricity. The BOS penalty compensates for this in our model. TF efficiencies are lower than $\mathrm{x}$-Si; and there is a $\sim 50 \%$ variation among the thin-films themselves. These variations impact total system cost as follows, assuming the area-related and power-related BOS costs are approximately equal.

System $\cos t\left(\frac{\$}{W p}\right)=$ Module $\cos t\left(\frac{\$}{W p}\right)+$ BOS $\cos t s \quad x-S i\left(\frac{\$}{W p}\right) *(1+$ BOS penalty $)$

where the BOS penalty is defined as:

$B O S$ penalty $=1 / 2\left(\frac{\text { Efficiency } x-\text { Si } \bmod u l e}{\text { Efficiency new } \bmod u l e}-1\right)$

The cost of the BOS penalty at break-even $\left(t_{b}\right)$ is:

$C_{B O S P \text { enalty }}=\sum_{x=1}^{t_{b}} n_{\text {yearlyTF }}(x) \times c_{B O S+\text { Penalty }}(x)-\sum_{x=1}^{t^{t}} n_{\text {yearlyTF }}(x) \times c_{B O S}(x)$

We model large, ground-mounted systems selling wholesale electricity - these can also be thought of as utility scale systems. We use a break-even price of $\$ 1 / \mathrm{Wp}$, which has been set as a goal for cost-competitiveness by the US DOE and other entities.[10] Table 2 shows the 
starting prices assumed for this model. Further discussion of the origin of these is included elsewhere.[11]

\begin{tabular}{|c|c|c|c|c|}
\hline Tech. & $\begin{array}{c}\text { BOS } \\
\text { penalty } \\
(\%)\end{array}$ & $\begin{array}{c}\text { Module } \\
\text { efficiency } \\
(\%)\end{array}$ & $\begin{array}{c}\text { Module + } \\
\text { BOS costs } \\
(\mathbf{\$} / \mathbf{W p})\end{array}$ & $\begin{array}{c}\text { Module } \\
\mathbf{+ B O S} \\
\text { with } 10 \% \\
\text { mark-up } \\
(\mathbf{\$} / \mathbf{W p})\end{array}$ \\
\hline $\mathrm{X}-\mathrm{Si}$ & 0 & 12 & $3.1+1.0=4.1$ & $\mathbf{4 . 5}$ \\
\hline $\mathrm{TF}$ & 15 & $\begin{array}{c}9(\mathrm{ex} . \\
\mathrm{CIS})\end{array}$ & $\begin{array}{c}2.85+1.15= \\
4.0\end{array}$ & $\mathbf{4 . 4}$ \\
\hline $\mathrm{TF}$ & 50 & $\begin{array}{c}6(\mathrm{ex} . \mathrm{a}- \\
\mathrm{Si})\end{array}$ & $\begin{array}{c}2.85+1.5= \\
4 . .4\end{array}$ & $\mathbf{4 . 8}$ \\
\hline
\end{tabular}

Table 2. Approx. PV system prices for 2004.[1] The system prices, assuming best practice installations and a $10 \%$ mark-up for the system integrator's profit, are indicated in bold type.

The results are presented in Table 3 . As the growth rate for TF increases to $40 \%$ and greater, the TF systems reach the break-even point before $x-S i$ systems and the cost gaps decrease significantly. The cost gaps decrease on the order of $50-70$ billion USD as the TF growth rate increases from $30 \%$ to $70 \%$. Varying the BOS penalty from $50 \%-15 \%$ yields a decrease in the cost gap of $\sim 10$ billion USD.

\begin{tabular}{|c|c|c|c|c|c|}
\hline \multicolumn{6}{|c|}{ LARGE FIELD SYSTEMS (Break even \$1/Wp) } \\
\hline \multicolumn{6}{|c|}{ Penalty $15 \%$} \\
\hline $\begin{array}{c}\text { Growth rate of } \\
\text { thin-film (\%) }\end{array}$ & $30 \%$ & $40 \%$ & $50 \%$ & $60 \%$ & $70 \%$ \\
\hline $\begin{array}{l}\text { First to reach } \\
\text { break-even }\end{array}$ & $\begin{array}{l}\mathrm{x}-\mathrm{Si} \\
\text { and } \\
\mathrm{TF}\end{array}$ & TF & TF & TF & TF \\
\hline Break-even year & 2022 & 2020 & 2018 & 2017 & 2016 \\
\hline $\begin{array}{l}\text { Module cost at } \\
\text { break-even } \\
\text { (USDNp) }\end{array}$ & $\begin{array}{c}0.6 \\
(\mathrm{x}-\mathrm{Si}) \\
\text { and } \\
0.7 \\
(\mathrm{TF})\end{array}$ & 0.6 & 0.6 & 0.5 & 0.5 \\
\hline $\begin{array}{c}\text { Cum. production } \\
\text { TF (GW) }\end{array}$ & 29.3 & 45.9 & 52.7 & 72.2 & 85.1 \\
\hline $\begin{array}{l}\text { Cum. production } \\
\text { PV (GW) }\end{array}$ & 496.4 & 293.5 & 173.4 & 133.3 & 102.4 \\
\hline $\begin{array}{c}\text { Cost gap } \\
\text { (billion USD) }\end{array}$ & 153.7 & 149.4 & 120.3 & 90.9 & 74.9 \\
\hline \multicolumn{6}{|c|}{ Penalty $50 \%$} \\
\hline $\begin{array}{c}\text { Growth rate of } \\
\text { thin-film }(\%)\end{array}$ & $30 \%$ & $40 \%$ & $50 \%$ & $60 \%$ & $70 \%$ \\
\hline $\begin{array}{l}\text { First to reach } \\
\text { break-even }\end{array}$ & $x-S i$ & TF & TF & TF & NA \\
\hline Break-even year & 2022 & 2021 & 2019 & 2018 & NA \\
\hline $\begin{array}{c}\text { Module cost at } \\
\text { break-even } \\
\text { (billion USD/Wp) }\end{array}$ & 0.6 & 0.5 & 0.5 & 0.4 & NA \\
\hline $\begin{array}{l}\text { Cum. production } \\
\text { TF (GW) }\end{array}$ & 29.3 & 64.2 & 79.0 & 115.5 & NA \\
\hline $\begin{array}{l}\text { Cum. production } \\
\text { PV (GW) }\end{array}$ & 496.4 & 381.7 & 225.6 & 173.4 & NA \\
\hline $\begin{array}{c}\text { Cost gap } \\
\text { (billion USD) }\end{array}$ & 156.6 & 159.9 & 136.1 & 102.6 & NA \\
\hline
\end{tabular}

Table 3. Growth scenarios and cost gaps based for various growth rates and BOS penalties. NA denotes a growth scenario is not valid because the TF cumulative production exceeds the $30 \%$ cap on PV growth before the break-even point.

\section{SYSTEM COMPONENTS ANALYSIS}

A serious limitation of the experience curve model is the risk of predicting physically impossible, low costs. We address this by estimating a lower bound for achievable costs.

The major manufacturing cost components of a TF module are: capital costs, materials, energy, maintenance, and labor. The components that are active participate in the conversion of sunlight to electricity (semiconductors and contacts), and those that are inactive protect the module from the environment and connect it to an outside circuit.

Table 4 presents an estimate of current and future costs of key components. The cost estimates for optimized components assumes: technical improvements, economies-of-scale, and efficient make/buy decisions (e.g., putting a glass plant on the front of a TF module manufacturing plant, or making EVA on-site instead of buying it). Large manufacturing plant volumes (1-3 GWp/yr or more) and far-future time horizons (10-20 years) are assumed. Table 5 translates manufacturing costs (in $\$ / \mathrm{m}^{2}$ ) into module costs (in $\$ / \mathrm{Wp}$ ), which requires an efficiency assumption. Estimated costs have been assumed towards the lower end of the 'ultimate cost' ranges in Table 4, and they have a relatively large error bar.

\begin{tabular}{|c|c|c|}
\hline COMPONENT & \multicolumn{2}{|c|}{ MAJOR COST ASPECTS } \\
\hline Active & Current & Optimized \\
\hline $\begin{array}{l}\text { Thin-film light } \\
\text { absorber }\end{array}$ & $\begin{array}{c}\text { Materials } \sim \$ 2- \\
\$ 50 / \mathrm{m}^{2} ; \text { process } \\
\sim \$ 7-\$ 40 / \mathrm{m}^{2} ; \\
\text { maintenance } \sim \$ 4- \\
10 / \mathrm{m}^{2} ; \text { energy } \\
\sim \$ 3-\$ 10 / \mathrm{m}^{2} \\
\end{array}$ & $\begin{array}{l}\text { Materials } \sim \$ 1- \\
\$ 20 / \mathrm{m}^{2} ; \text { process } \\
\sim \$ 1-\$ 5 / \mathrm{m}^{2}, \\
\text { maintenance } \\
\sim \$ 1 / \mathrm{m}^{2} ; \text { energy } \\
\sim \$ 1-\$ 3 / \mathrm{m}^{2} \\
\end{array}$ \\
\hline Absorber partners & $\$ 3-\$ 10 / \mathrm{m}^{2}$ & $\$ 1-\$ 2 / m^{2}$ \\
\hline Top contact & $\$ 3-\$ 10 / \mathrm{m}^{2}$ & $\$ 1-\$ 2 / \mathrm{m}^{2}$ \\
\hline Bottom contact & $\$ 3-\$ 10 / \mathrm{m}^{2}$ & $\$ 1 / \mathrm{m}^{2}$ \\
\hline Optional substrate & $\$ 2-\$ 15 / \mathrm{m}^{2}$ & $\$ 1-\$ 5 / \mathrm{m}^{2}$ \\
\hline \multicolumn{3}{|l|}{ Inactive } \\
\hline $\begin{array}{c}\text { Top transparent } \\
\text { barrier }\end{array}$ & $\$ 10-\$ 25 / \mathrm{m}^{2}$ & $\$ 4-\$ 10 / \mathrm{m}^{2}$ \\
\hline Bottom barrier & $\$ 8-\$ 15 / \mathrm{m}^{2}$ & $\$ 3-\$ 8 / \mathrm{m}^{2}$ \\
\hline $\begin{array}{l}\text { Connection to } \\
\text { outside circuit }\end{array}$ & $\$ 4-6 / m^{2}$ & $\$ 2 / \mathrm{m}^{2}$ \\
\hline Edge barrier & $\$ 4-6 / \mathrm{m}^{2}$ & $\$ 2 / \mathrm{m}^{2}$ \\
\hline Mounting scheme & $\$ 0-\$ 8 / \mathrm{m}^{2}$ & $\$ 0-\$ 4 / \mathrm{m}^{2}$ \\
\hline Total Active & $\begin{array}{c}\$ 27 / \mathrm{m}^{2}- \\
\$ 155 / \mathrm{m}^{2} ; \\
\text { average } \$ 91 / \mathrm{m}^{2}\end{array}$ & $\$ 8 / \mathrm{m}^{2}-\$ 39 / \mathrm{m}^{2}$ \\
\hline Total Inactive & $\begin{array}{l}\$ 26 / \mathrm{m}^{2}-\$ 60 / \mathrm{m}^{2} \\
\text { average } \$ 43 / \mathrm{m}^{2}\end{array}$ & $\$ 11 / \mathrm{m}^{2}-\$ 24 / \mathrm{m}^{2}$ \\
\hline Total & $\begin{array}{c}\$ 53 / \mathrm{m}^{2}- \\
\$ 215 / \mathrm{m}^{2} ; \\
\text { average } \$ 134 / \mathrm{m}^{2}\end{array}$ & $\$ 19 / \mathrm{m}^{2}-\$ 65 / \mathrm{m}^{2}$ \\
\hline
\end{tabular}

Table 4. Estimates of current and future module cost components. 


\begin{tabular}{llc}
\hline & \multicolumn{1}{c}{ Now $^{\mathrm{a}}$} & \multicolumn{1}{c}{ Ultimate } \\
\hline CdTe & $\$ 1.5 / \mathrm{Wp} @ 8 \%$ & $\$ 0.2 / \mathrm{Wp} @ 14 \%$ \\
\hline CIS & $\begin{array}{l}\$ 1.8-\$ 2.5 / \mathrm{Wp} \\
\text { (projected) @11\% }\end{array}$ & $\$ 0.2 / \mathrm{Wp} @ 16 \%$ \\
\hline Thin-film Si & $\$ 2-3 \$ / \mathrm{Wp} @ 7 \%$ & $\$ 0.5 / \mathrm{Wp} @ 11 \%$ \\
\hline Table 5. Present and ultimate module cost estimates $\$ / \mathrm{Wp})$ \\
${ }^{\mathrm{a} T h i s}$ assumes $\sim 25 \mathrm{MWp} / \mathrm{yr}$ steady-state production (which \\
only exists for CdTe and a-Si); for CIS, this is a projection.
\end{tabular}

We do not study $\mathrm{x}-\mathrm{Si}$ in detail here, but component analyses have been performed in previous studies.[12] Achievable costs of 1 USD/Wp were estimated for a production level of $500 \mathrm{MWp} / \mathrm{yr}$. Further cost reductions to 0.8 and 0.9 USD/Wp (for poly and single crystal cells respectively) may be possible.[12] Note the gap between TF and x-Si ultimate costs, a portion of which may be based on differences in assumptions. Our analysis for thin-films should be considered optimistic, because we use numbers in the low range of Table 4, and the high efficiencies predicted in Table 5. Somewhat less optimistic numbers would meet our experience curve trajectory as well, as shown in Table 6.

\begin{tabular}{ccc}
\hline & $\mathbf{x - S i}$ & TFs \\
\hline $\begin{array}{c}\text { Lowest experience } \\
\text { curve price }\end{array}$ & $\$ 0.75 / \mathrm{Wp}$ & $\$ 0.5 / \mathrm{Wp}$ \\
\hline $\begin{array}{c}\text { Bottom-up } \\
\text { analysis: Cost }\end{array}$ & $\begin{array}{c}\$ 1 / \mathrm{Wp} \text { (but with } \\
\text { room for } \\
\text { reductions) }\end{array}$ & $\$ 0.2-\$ 0.5 / \mathrm{Wp}$ \\
\hline $\begin{array}{c}\text { Bottom-up cost } \\
\text { plus 10\% mark-up }\end{array}$ & $\$ 1.1 / \mathrm{Wp}$ & $\$ 0.22-\$ 0.55 / \mathrm{Wp}$ \\
\hline $\begin{array}{l}\text { Table 6. Comparison of cost projections for modules from } \\
\text { experience curve and system component analyses. }\end{array}$
\end{tabular}

The area-related BOS components will become less expensive as module efficiency increases. The active components of the BOS can be expected to improve technically; and the inactive component costs should decrease with increasing volumes of production. Based on these predicted improvements, our experience curve projections should also be consistent with achievable reductions in BOS costs.

\section{CONCLUSIONS}

Several key conclusions emerged from this study:

- PV technology choice significantly affects growth scenarios. Our technologydisaggregated experience curve model suggests that if new, low-intrinsic cost technologies grow faster, the societal cost of reaching a cost-competitive point for $\mathrm{PV}$ will be reduced (up to 70 billion USD) as compared to a scenario where $\mathrm{x}$-Si PV modules retain their current level of dominance.

- Several thin-film technologies show low intrinsic costs and the potential to reach the low module costs projected by the experience curve. This result is derived from system component analyses of a-Si, CIS, and CdTe each of which met projected costs.
- Although a new technology may be the longterm, lowest cost option due to its intrinsic costs, its real-time costs may prevent it from competing on the market. This points to two important measures to be considered: developing a better ability to assess intrinsic costs, and introducing competitive programs to facilitate market entry for low intrinsic cost technologies. These measures are likely to be important for many other energy technologies, and indeed for successfully addressing the major global energy challenges.

\section{ACKNOWLEDGEMENTS}

JET thanks the Santa Fe Institute and the Earth Institute, Columbia University, for funding this research. The authors thank Vijay Modi for insightful comments. NREL's contribution to this work was completed under DOE Contract No. DE-AC38-99-G010337 with the U.S. Department of Energy and is subject to a government license.

\section{REFERENCES}

1. Strategies Unlimited, Photovoltaic Manufacturer Shipments, 2004-2005.

2. Margolis, R.M. "Photovoltaic Technology Experience Curves and Markets", in NCPV and Solar Program Review Meeting, 2003, Denver, Colorado.

3. Schaeffer, G.J., et al., Learning from the Sun: Final Report of the Photex Project, 2004, Energy Research Centre of the Netherlands.

4. van der Zwaan, B. and A. Rabl, "The learning potential of photovoltaics: implications for energy policy", Energy Policy 32, 2004, pp. 1545-1554.

5. Keshner, M.S. and R. Arya, Study of Potential Cost Reductions Resulting from Super-LargeScale Manufacturing of PV Modules, 2004, NREL, Golden, Colorado.

6. Zweibel, K., TW Challenge, NREL/TP-52038350, 2005.

7. IEA, Experience Curves for Energy Technology Policy. 2000: OECD/IEA.

8. Dutton, J.M. and A. Thomas, "Treating Progress Functions as a Managerial Opportunity", Academy of Management Review 9, 1984, pp. 235-247.

9. First Solar Press Release, First Solar Announces Tripling of Production Capacity, March 24, 2005.

10. US DOE, Solar Energy Technologies Multi-Year Program Plan 2007-2011, 2005.

11. Trancik, J.E., K. Zweibel, and V. Modi, Technology-Sensitive Growth Scenarios for Photovoltaics, in review, 2005.

12. Bruton, T.M., Music FM - Five Years on Fantasy or Reality, 18th European Photovoltaic Solar Energy Conference, 2002. 